\title{
Geomechanical Assessments of Simultaneous Operation in the Case of Transition from Open Pit to Underground Mine in Vietnam
}

\author{
Zbigniew Niedbalski ${ }^{1}$, Phu Minh Vuong Nguyen ${ }^{2,}$, and Eleonora Widzyk-Capehart ${ }^{2}$ \\ ${ }^{1}$ AGH University Science and Technology, Faculty of Mining and Geoengineering, \\ A. Mickiewicza Av. 30, 30-059 Krakow, Poland \\ ${ }^{2}$ AMTC, University of Chile
}

\begin{abstract}
Nowadays, for a number of reasons, many open pit mines are considering a transition from Open Pit (OP) to Underground (UG) to remain competitive. In OP-UG transition, UG operation is operated simultaneously with the OP operation for a certain period of time. Guidelines for the simultaneous operation of OP and UG are very difficult to establish, as there are very few case studies available. Yet, because of the OP-UG interactions; the operation has a higher safety, technical and management requirements than the OP or UG methods when considered separately. In Vietnam, Cao Son is one of many OP mines, which decided to change the operational system from OP to UG. Simultaneous operation started in 2015 and will be conducted until 2030 when the OP mine Cao Son ends its mining activities. In this paper, selected geomechanical considerations of the simultaneous operation are presented. A number of numerical modelling calculations using finitedifference software with code FLAC were carried out for calibration process, slope stability analysis and the OP-UG interaction analysis for the Cao Son - Khe Cham II-IV mine. Based on the results obtained from numerical modelling, the geomechanical assessments of simultaneous operation Cao Son - Khe Cham II-IV are discussed in this paper. Key words - OP-UG transition, OP-UG interaction, numerical modelling, slope stability.
\end{abstract}

\section{Introduction}

Over time, open pit mines tend to go deeper and become larger. However, with the increasing depth of exploitation, there are a number of difficulties that make further exploitation unsafe and/or unprofitable. Consequently, changing the way of mining is required to continue the life of the OP mines. From the technological and mining costs perspectives, the only solution for further extraction are underground methods, which would allow the access to the deposit below the bottom of the open pit $[1,2]$. Therefore, in transition from OP to UG, both operations will often be run simultaneously for a certain period of time. Underground operation causes subsidence, slope movements, discontinuous deformations and change of hydrogeological conditions. In the case of underground operation located below the open pit mine, slope strain

* Corresponding author: nguyen.pmv@amtc.cl 
can be expected as a result of subsidence induced by underground exploitation. Changes in physical and mechanical properties of rock mass, groundwater levels and the state of stress inside the slope can lead to slope deformation. The negative OP-UG interaction cases [3-5] provide a clear warning as to the possible impact of underground mining on open pit mines. Therefore, it is necessary to carry out more research and analysis on slope stability of open pits affected by underground mining and, due to the different geological conditions and the technology application, any such case should be analyzed individually.

Currently, the Vietnam coal mining is a very important part of the national economy and hard coal is mined mainly by the OP method. In the coal mining of Vietnam, the decision to switch from OP mining to UG mining was taken for several reasons, including: technological possibilities, economic and environmental conditions and social aspects [6]. Cao Son is an OP mine located in coal basin Cam Pha, Quang Ninh. The OP mine Cao Son is decided to change the operation system from OP to UG (Khe Cham II-IV). Simultaneous operation started in 2015 and will be conducted until 2030. To estimate the simultaneous operation Cao Son - Khe Cham II-IV from point of view of safety, the surface and subsurface strain fields generated by simultaneous operation were investigated by using numerical modelling with FDM code. Based on the results obtained, several geomechanical assessments are presented as a case study of Cao Son - Khe Cham II-IV.

\section{Case study: simultaneous operation Cao Son - Khe Cham II-IV}

The OP anthracite mine Cao Son is located in the Cam Pha coal basin in the Quang Ninh province of Vietnam. Cao Son is about $150 \mathrm{~km}$ eastward from the capital city - Hanoi, at the altitude of 100-150 m a.s.l. Cao Son mine has decided to make a transition from OP to UG in 2015. The UG operation, Khe Cham II-IV, is being operated under Cao Son. Simultaneous operation (Cao Son and Khe Cham II-IV) will be conducted until 2030 when the OP mine Cao Son ends its mining activities (Fig. 1). The Quaternary period rock mass consists mainly of gravel, sand, and rolled fill. It is approximately $20 \mathrm{~m}$ thick and in some places $150 \mathrm{~m}$ thick. The Triassic rock mass is located under the Quaternary period rock and consists of hard rocks: conglomerate $(16 \%)$, sandstone $(48 \%)$, mudstone $(25 \%)$, claystone $(3 \%)$ and coal $(8 \%)$. Thickness of the Triassic period rock mass ranges from $500 \mathrm{~m}$ to $700 \mathrm{~m}$ [6].

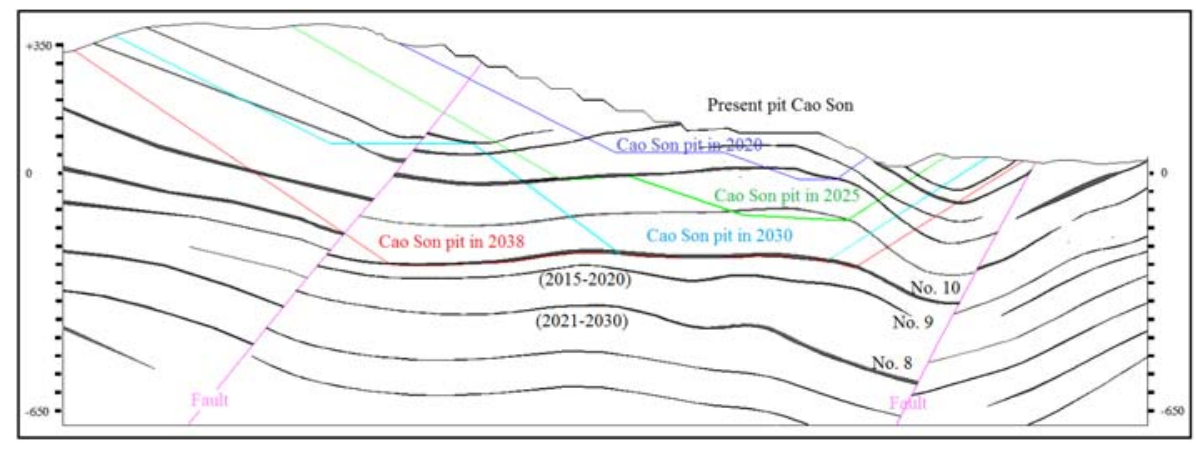

Fig. 1. Exploitation plan in region Cao Son and Khe Cham II-IV in the North-South cross section

The hydrogeological conditions of the Cao Son and Khe Cham II-IV can be characterised as follows [6]: presence of surface water from local streams (Bang Nau, Khe Cham) and from open pits due to rainfall: average rainfall is $4.7-8.0 \mathrm{~mm}$ /day and up to $350 \mathrm{~mm} /$ day in the rainy season. Surface water is the main source that supplies water to the Triassic rock mass. Groundwater in the Quaternary and dumping ground exists only in the rainy season. 
Underground water in the Triassic rock mass is present in the slits of rock mass. The measured filtration ratio is $0.038 \mathrm{~m}$ per day. Water is mainly in conglomerate and sandstone. Water does not occur or occurs in very small quantities in the layers of mudstone and claystone and in the fault zones.

Cao Son mine operation will be completed in 2038 in the coal seam No. 10 located at depth of $300 \mathrm{~m}$ b.s.l. Under the bottom of the Open Pit Cao Son, UG operation is planned to extract coal seam No. 9 with a thickness of $2 \mathrm{~m}$ (2015-2020) and No. 8 with a thickness of $3 \mathrm{~m}$ (2021-2030). The average size of the UG operation Khe Cham II-IV is 4,300 × 1,600 $\mathrm{m}$ [6].

\section{Numerical modelling}

Prediction of interaction between UG and OP was carried out with the application of FLAC 2D software based on Finite Difference Method [7]. It was assumed that the rock mass was stratified with the properties according to the elastic-plastic model of Mohr-Coulomb. The initial model was solved as an elastic model to obtain the initial stress conditions. The vectors and speeds of displacements were zeroed. In the next step, the "null" value was assigned to the model of the caved zone and the fractured zone (stresses were zeroed in these areas), and re-assigning of the Mohr-Coulomb model to the rock mass with the assumed parameters was made, followed by new set of calculations. In purpose to define the mechanical properties of rock mass for numerical modelling, the calibration data process was carried out base on determining the values of mechanical parameters of rock mass caved zone and fractured zone for which the maximum values of vertical displacement obtained with assumption 'worst case' is in accordance with the Knothe theory [8]. Because of slight difference in the mechanical properties of the rock mass types in the Cao Son and Khe Cham II-IV regions, rock mass was divided into 2 main groups of rocks: a group of sandstone and conglomerate and a group of claystone, mudstone and coal. The correlation between laboratory mechanical parameters and rock mass parameters is commonly used for numerical modelling. Due to the lack of RMR studies for the Cao Son and Khe Cham II-IV regions, it was assumed that the strength parameters should be reduced to $25 \%$ and the deformation parameters to $50 \%$ [9]. The mechanical parameters used for numerical modelling is presented in Table 1.

Table 1. Mechanical parameters of rock mass used for numerical modelling

\begin{tabular}{|c|c|c|c|c|c|c|}
\hline Type of rock mass & $\begin{array}{c}\text { Cohesion } \\
c[\mathrm{MPa}]\end{array}$ & $\begin{array}{c}\text { Fiction } \\
\text { angle } \\
\theta\left[{ }^{\circ}\right]\end{array}$ & $\begin{array}{c}\text { Density } \\
\gamma\left[\mathbf{k g} / \mathrm{m}^{3}\right]\end{array}$ & $\begin{array}{c}\text { Tensile } \\
\text { strength } \\
\sigma^{t}[\mathrm{MPa}]\end{array}$ & $\begin{array}{c}\text { Bulk } \\
\text { modulus } \\
K \text { [GPa] }\end{array}$ & $\begin{array}{c}\text { Shear } \\
\text { modulus } \\
G \text { [GPa] }\end{array}$ \\
\hline $\begin{array}{l}\text { Group of sandstone } \\
\text { and conglomerate }\end{array}$ & 1.27 & 28 & 2580 & 0.51 & 2.06 & 1.37 \\
\hline $\begin{array}{l}\text { Group of claystone, } \\
\text { mudstone and coal }\end{array}$ & 0.52 & 29 & 2370 & 0.325 & 1.14 & 0.74 \\
\hline Coal & 0.6 & 27 & 1500 & 0.305 & 1.09 & 0.68 \\
\hline
\end{tabular}

To determine the geometry of the model, the average heights of caved zone and fractured zone were calculated using the following formulas [10]:

$$
h_{c}=\frac{100 g}{c_{1} g+c_{2}} \text { and } h_{f}=\frac{100 g}{c_{3} g+c_{4}}
$$

where: $h_{c}$ - height of caved zone, $\mathrm{m} ; h_{f}$ - height of fractured zone, $\mathrm{m} ; g$ - average thickness of coal seam, $\mathrm{m} ; c_{1}, c_{2}, c_{3}, c_{4}$ - coefficients are shown in Table 2.

It was assumed that the height of caved zone and fractured zone are the same for all calculation variants and their values were determined according to Equation 1. For coal 
seam No. 9 the height of caved zone and fractured zone are $10 \mathrm{~m}$ and $45 \mathrm{~m}$, respectively. Deformation and strength parameters of caved and fractured zones were selected according to the investigation of Nawrot [11].

Table 2. Coefficients for average heights of caved zone and fractured zone [10]

\begin{tabular}{|l|c|c|c|c|c|}
\hline \multirow{2}{*}{ Type of rock mass } & \multirow{2}{*}{$\begin{array}{c}\text { Compressive strength, } \\
{[\mathbf{M P a}]}\end{array}$} & \multicolumn{4}{|c|}{ Coefficients } \\
\cline { 3 - 6 } & $>40$ & $\boldsymbol{c}_{\mathbf{1}}$ & $\boldsymbol{c}_{\mathbf{2}}$ & $\boldsymbol{c}_{\mathbf{3}}$ & $\boldsymbol{c}_{\mathbf{4}}$ \\
\hline Strong and hard & $20-40$ & 2.1 & 16 & 1.2 & 2 \\
\hline Medium strong & $<20$ & 4.7 & 19 & 1.6 & 3.6 \\
\hline Soft and weak & 6.2 & 32 & 3.1 & 5 \\
\hline
\end{tabular}

For caved zone: the values of strength parameters are 0 and the values of deformation parameters are 20-40 times lower than the values of roof rock. For fractured zone: the value of strength parameters are 1.25-2 times lower, and the value of deformation parameters are 2-5 times lower than the values of roof rock. Roof rocks located above coal seam No. 9 are mainly conglomerate and sandstone [3]; thus, the mechanical parameters of caved and fractured zones were determined based on the mechanical parameters of the sandstone and conglomerate rock group. Density of fractured zone is assumed to be close to the value of rock mass density. Density of caved zone is calculated using the following formulas [12]:

$$
\gamma_{c}=\frac{y_{r m}}{b} \text { and } b=\frac{c_{1}+c_{2}}{100}+1
$$

where: $\gamma_{c}-$ density of caved zone, $\left[\mathrm{kg} / \mathrm{m}^{3}\right] ; y_{r m}-$ density of rock mass, $\left[\mathrm{kg} / \mathrm{m}^{3}\right] ; b-$ bulking factor, $-; \mathrm{g}, c_{1}, c_{2}-$ defined earlier in Equation 1.

Computational mechanical parameters of caved and fractured zones are shown in Table 3 after the calibration process, which consists in finding the values of the mechanical parameters of fractured zone and caved zone to obtain the subsidence value close to the coal seam thickness.

Table 3. Mechanical properties of caved zone and fractured zone used for numerical modelling

\begin{tabular}{|l|c|c|c|c|c|c|}
\hline \multicolumn{1}{|c|}{ Type of rock mass } & $\begin{array}{c}\text { Cohesion } \\
\boldsymbol{c}[\mathbf{M P a}]\end{array}$ & $\begin{array}{c}\text { Fiction } \\
\text { angle } \\
\boldsymbol{\theta}\left[^{\circ}\right]\end{array}$ & $\begin{array}{c}\text { Density } \\
\gamma\left[\mathbf{k g} / \mathbf{m}^{3}\right]\end{array}$ & $\begin{array}{c}\text { Tensile } \\
\text { strength } \\
\boldsymbol{\sigma}^{t}[\mathbf{M P a}]\end{array}$ & $\begin{array}{c}\text { Bulk } \\
\text { modulus } \\
\boldsymbol{K}[\mathbf{G P a}]\end{array}$ & $\begin{array}{c}\text { Shear } \\
\text { modulus } \\
\boldsymbol{G}[\mathbf{G P a}]\end{array}$ \\
\hline $\begin{array}{l}\text { Group of sandstone } \\
\text { and conglomerate }\end{array}$ & 1.27 & 28 & 2580 & 0.51 & 2.06 & 1.37 \\
\hline Caved zone & $\mathbf{0}$ & $\mathbf{1 0}$ & $\mathbf{2 1 0 0}$ & $\mathbf{0}$ & $\mathbf{0 . 0 8 5}$ & $\mathbf{0 . 0 5 6}$ \\
\hline Fractured zone & $\mathbf{0 . 9 0 8}$ & $\mathbf{1 9}$ & $\mathbf{2 5 0 0}$ & $\mathbf{0 . 3 6 5}$ & $\mathbf{0 . 7 9 3}$ & $\mathbf{0 . 5 2 7}$ \\
\hline
\end{tabular}

The strength parameters of fault for numerical modelling were selected: friction angle 200, cohesion $4 \mathrm{kPa}$, tensile strength $0 \mathrm{kPa}$ [6]. Due to the lack of data on deformation parameters of faults in the Cao Son and Khe Cham II-IV regions, deformation parameters of the fault were calculated according to the formula developed by Itasca [7]:

$$
k_{s}=k_{n}=10 \cdot \max \left[\frac{K+\frac{4}{3} G}{\Delta z_{\min }}\right]
$$


where: $K$ and $G$ are the bulk and shear moduli, respectively, GPa; $\Delta z_{\min }$ is the smallest width of an adjoining zone in the normal direction, $\mathrm{m} ; k_{n}$ and $k_{s}$ are the normal and shear stiffness, respectively, $\mathrm{GPa} / \mathrm{m}$.

After the calculation according to Equation 3, a set of mechanical properties of faults used for numerical modelling are determined: $k_{n}=k_{s}=2.6 \mathrm{GPa} / \mathrm{m}$, friction angle 200, cohesion $4 \mathrm{kPa}$, tensile strength $0 \mathrm{kPa}$.

\section{Results, analysis and discussions}

Based on the exploitation plan (Chapter 2) for Cao Son and Khe Cham II-IV, the following observations can be drawn for coal seam No. 9: by the end of 2016 (Fig. 2a), only two panels with an average mine face length of $150 \mathrm{~m}$ would have been mined. Therefore, the most important issue is to determine the location, where to start the UG operation to ensure maximum slope stability and continuous progress of UG operation. By 2020 (Fig. 2b), coal seam No. 9 will be completely exploited; thus, the pit in 2020 may be affected by UG operation in coal seam No. 9. Numerical calculations were performed to show the impact of UG operation on coal seam No. 9 (Khe Cham II-IV) on advanced phases of OP (Cao Son) using FDM software program with the 2D FLAC code. For each variant, characteristic points were set on the surface of the slope during underground operation. From those characteristic points, values of displacements, velocity vectors were read and used with plasticity indicator to analyse the slope stability at each advance phase of OP. Calculations were made for the pit in 2016 and 2020 year.

a)

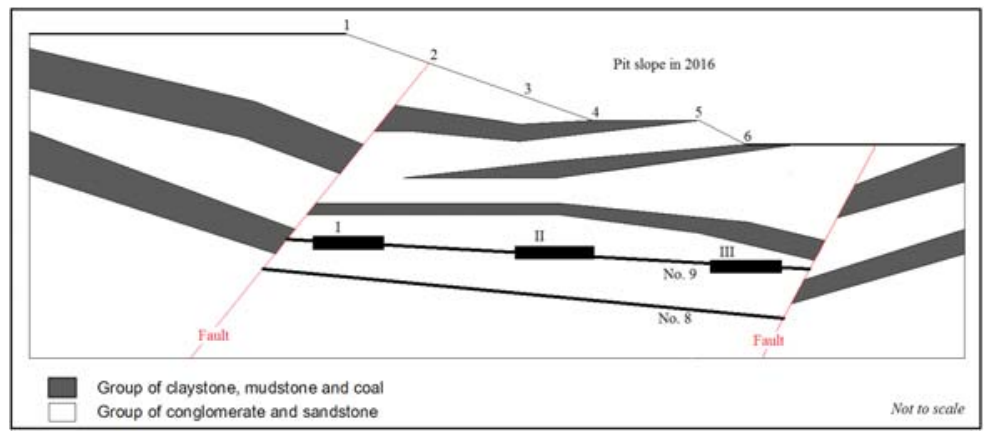

b)

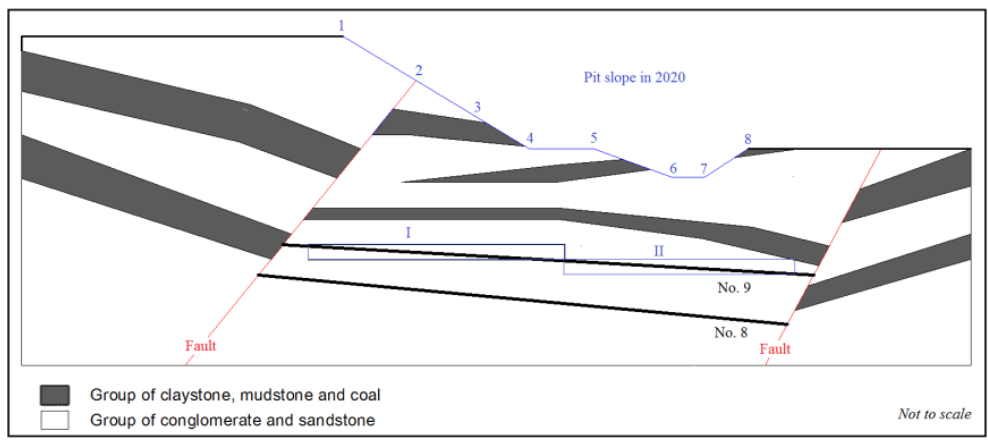

Fig. 2. 2D numerical model for the stage of UG exploitation a) to 2016, b) to 2020

The purpose of this analysis was to determine the location of where to start the UG operation and to indicate the direction of exploitation in the coal seam No. 9 (Fig. 2a). 
Numerical calculations were carried out to show the influence of UG operation on the two panels (average mining face length is $150 \mathrm{~m}$ ) on the slope in 2016 with different panel locations (left - I, central - II, right - III). Table 4 shows displacements and velocity vectors read from the characteristic points located on the slope surface with different locations of two UG long wall panels. Velocity vectors measured on the slope surface are low (much less than transitional value indicating a possibility of unstable state: $1 \cdot 10^{-6}$ ) with different locations of two long wall panels. Vertical displacements in case of location I are approx. $1 \mathrm{~m}$ (upper part of the pit) while vertical displacements in case of location II and III are lower with obtained value of $0.6 \mathrm{~m}$. Horizontal displacements of all cases are approx. $20 \mathrm{~cm}$ (Tab. 4). These displacements do not signify instability, however, the displacements induced by Case I would cause difficulties during OP exploitation, such as, OP transportation. Generally, obtained results in Table 4 indicate that initial exploitation (two long wall panels) has a slight influence on slope stability of the 2016 pit. The location where the UG operation begins should be selected with the shortest distance to the first working (shafts) and further UG exploitation will have a minimum affect on slopes stability over time. Location II and III have been shown to be better than location I from the point of view of their influence on slope stability; however, location III is centered below the bottom of the mine in 2016 . Therefore, it is recommended to start underground operation at location II.

Table 4. Displacements and velocity vectors along the slope surface in 2016 with different locations of the two UG panels

\begin{tabular}{|c|l|c|c|c|c|c|}
\hline \multirow{2}{*}{$\begin{array}{c}\text { Location } \\
\text { UG } \\
\text { panels }\end{array}$} & \multicolumn{1}{|c|}{ Measured parameters } & \multicolumn{4}{c|}{ Chosen points located on the slope surface } \\
\cline { 2 - 7 } & & $\mathbf{1}$ & $\mathbf{2}$ & $\mathbf{4}$ & $\mathbf{5}$ & $\mathbf{6}$ \\
\hline \multirow{4}{*}{ I } & Vertical displacements $[\mathrm{m}]$ & -1.077 & -1.048 & -0.047 & -0.007 & -0.006 \\
\cline { 2 - 7 } & Horizontal Displacements [m] & 0.228 & -0.070 & 0.080 & 0.090 & 0.080 \\
\cline { 2 - 7 } & Vertical velocity vectors $\left[10^{-6}\right]$ & -0.172 & -0.036 & -0.010 & -0.001 & -0.006 \\
\cline { 2 - 7 } & Horizontal velocity vectors $\left[10^{-6}\right]$ & 0.051 & 0.092 & 0.148 & 0.092 & 0.080 \\
\hline \multirow{4}{*}{ II } & Vertical displacements [m] & -0.116 & -0.246 & -0.593 & -0.121 & -0.028 \\
\cline { 2 - 7 } & Horizontal Displacements $[\mathrm{m}]$ & 0.197 & 0.237 & -0.074 & -0.161 & -0.043 \\
\cline { 2 - 7 } & Vertical velocity vectors $\left[10^{-6}\right]$ & -0.193 & -0.073 & -0.010 & -0.020 & -0.002 \\
\cline { 2 - 7 } & Horizontal velocity vectors $\left[10^{-6}\right]$ & 0.247 & 0.177 & 0.133 & 0.075 & 0.037 \\
\hline \multirow{3}{*}{ III } & Vertical displacements [m] & -0.008 & -0.007 & -0.100 & -0.442 & -0.555 \\
\cline { 2 - 7 } & Horizontal Displacements $[\mathrm{m}]$ & 0.031 & 0.048 & 0.145 & 0.213 & 0.014 \\
\cline { 2 - 7 } & Vertical velocity vectors $\left[10^{-6}\right]$ & -0.124 & -0.022 & -0.080 & -0.015 & -0.060 \\
\cline { 2 - 7 } & Horizontal velocity vectors $\left[10^{-6}\right]$ & 0.147 & 0.191 & 0.193 & 0.119 & 0.087 \\
\hline
\end{tabular}

The aim of next analysis is to determinate a sequence of UG operation that minimise the UG impact on pit slope 2020 (Fig. 2b). Numerical calculations were carried out to show the influence of UG operation in coal seam No. 9 on slope in 2020 with two different sequences. The adequate direction of UG operation in coal seam No. 9 was determined to minimise its impact on the stability of the slope 2020. Two options were taken into consideration: first right half then left half (right-left) and first left half then right half (leftright). Displacements and velocity vectors on the slope surface in 2020 with two directions of UG exploitation are presented in Table 5. Velocity vectors obtained from all calculations are low (much less than transitional value indicating a possibility of unstable state $1 \cdot 10^{-6}$ ). Initially, slope 2020 can be considered to be stable during UG operation in coal seam No. 9. First step is exploitation of first half. With the UG operation in left half (I), the maximum vertical displacement reached $1.7 \mathrm{~m}$ (point 2) while the horizontal displacement is $0.8 \mathrm{~m}$ (point 1). With the UG operation in right half (II), the vertical displacement was about 1.2 $\mathrm{m}$ (points 6 and 7), while the horizontal displacement was approximately $0.45 \mathrm{~m}$ (point 4) 
(Tab. 5). This means that the displacements caused by the UG operation in the left half (I) are greater the displacements caused by the UG operation in the right half (II). Thus, the UG operation in the right half (II) affects the slope lower than the UG operation in the left half (I). This can be explained by the fact that the left part of slope is larger than the right part of the slope. Second step is exploitation of first half. In the left-right UG operation, the vertical displacements reached $0.8-2 \mathrm{~m}$ along the slope, while the maximum horizontal displacement was about $1.2 \mathrm{~m}$ (point 1). In the "right-left" UG operation, the vertical displacements obtained were $0.9-1.9 \mathrm{~m}$ along the slope, while the maximum horizontal displacement was $1 \mathrm{~m}$ (point 1) (Tab. 5). It shows that the "right-left" UG operation is slightly more advantageous than the "left-right" UG operation. Thus, the final impact induced by the "left-right" UG operation is less than the final impact induced by the "right-left" UG operation. Obtained results indicate that UG exploitation in coal seam No. 9 influence slightly the slope stability of the 2020 pit and the left-right UG operation is recommended.

Table 5. Displacements and velocity vectors along the slope surface in 2020 with 2 different UG exploitation directions

\begin{tabular}{|c|c|c|c|c|c|c|c|}
\hline \multirow{2}{*}{\multicolumn{2}{|c|}{$\begin{array}{l}\text { Sequence of } \\
\text { operation }\end{array}$}} & \multirow{2}{*}{ Measured parameters } & \multicolumn{5}{|c|}{ Chosen points located on the slope surface } \\
\hline & & & 1 & 3 & 4 & 6 & 7 \\
\hline \multirow{8}{*}{$\begin{array}{l}\text { From left } \\
\text { hand side } \\
\text { to right } \\
\text { hand side }\end{array}$} & \multirow{4}{*}{$\begin{array}{l}\text { Left } \\
\text { half } \\
\text { (I) }\end{array}$} & Vertical displac. $[\mathrm{m}]$ & -1.382 & -1.584 & -0.930 & -0.033 & -0.006 \\
\hline & & Horizontal displac. [m] & 0.802 & 0.292 & -0.173 & 0.079 & 0.081 \\
\hline & & Vert. velocity vectors $\left[10^{-6}\right]$ & -0.124 & -0.266 & -0.047 & -0.003 & -0.002 \\
\hline & & Horiz. velocity vectors $\left[10^{-6}\right]$ & 0.290 & 0.470 & 0.110 & 0.140 & 0.078 \\
\hline & \multirow{4}{*}{$\begin{array}{l}\text { Right } \\
\text { half } \\
\text { (II) }\end{array}$} & Vertical displac. $[\mathrm{m}]$ & -1.614 & -2.058 & -1.783 & -1.235 & -1.114 \\
\hline & & Horizontal displac. $[\mathrm{m}]$ & 1.150 & 0.820 & 0.366 & 0.253 & 0.050 \\
\hline & & Vert. velocity vectors $\left[10^{-6}\right]$ & -0.346 & -0.174 & -0.156 & -0.083 & -0.070 \\
\hline & & Horiz. velocity vectors $\left[10^{-6}\right]$ & 0.398 & 0.451 & 0.216 & 0.307 & 0.143 \\
\hline \multirow{8}{*}{$\begin{array}{l}\text { From right } \\
\text { hand side } \\
\text { to left } \\
\text { hand side }\end{array}$} & \multirow{4}{*}{$\begin{array}{l}\text { Right } \\
\text { half } \\
\text { (II) }\end{array}$} & Vertical displac. $[\mathrm{m}]$ & -0.061 & -0.163 & -0.434 & -1.150 & -1.126 \\
\hline & & Horizontal displac. [m] & 0.112 & 0.230 & 0.416 & 0.088 & -0.131 \\
\hline & & Vert. velocity vectors $\left[10^{-6}\right]$ & -0.133 & -0.070 & -0.050 & -0.005 & -0.012 \\
\hline & & Horiz. velocity vectors $\left[10^{-6}\right]$ & 0.183 & 0.200 & 0.111 & 0.067 & 0.040 \\
\hline & \multirow{4}{*}{$\begin{array}{l}\text { Left } \\
\text { half } \\
\text { (I) }\end{array}$} & Vertical displac. $[\mathrm{m}]$ & -1.559 & -1.890 & -1.688 & -1.313 & -1.171 \\
\hline & & Horizontal displac. [m] & 1.020 & 0.592 & 0.338 & 0.147 & -0.038 \\
\hline & & Vert. velocity vectors $\left[10^{-6}\right]$ & -0.220 & -0.407 & -0.193 & -0.037 & -0.082 \\
\hline & & Horiz. velocity vectors $\left[10^{-6}\right]$ & 0.538 & 0.518 & -0.189 & 0.184 & 0.046 \\
\hline
\end{tabular}

\section{Conclusions}

The obtained results showed that all pit slopes were considered stable for various arrangements of UG exploitation. However, this does not entirely eliminates the possibility of slope displacement, which could negatively affect an OP operation. The impact of UG operation on OP slope stability is a continuous process related with the advance of both OP and UG exploitations. During the simultaneous operation, such as, Cao Son and Khe Cham II-IV, changes to slope geometry can also prevent the impact of UG exploitation. Hence, an appropriate scheduling and coordination of exploitation plan is required. Simultaneous operation is not a common mining technique, especially, for coal mining. Therefore, special actions should be taken to guide these types of operation, including: carrying out slope stability analysis for any advancing phase of open pit with the advance of UG operation; applying monitoring system to ensure slope stability by detecting any in-ground and surface movements; carrying out water drainage from pit bottom to prevent water inrush into UG workings; 
minimising blasting in both OP and UG Operation; minimising subsidence surface by using UG methods.

\section{References}

1. W.F. Visser, Optimization of the OP/UG Transition. Development of a Software Tool for Optimization of the Transition Depth and the Open Pit Slope Angle - Main report. Technische Universiteit Delft (2006)

2. P.M.V. Nguyen, Z. Niedbalski, Numerical modelling of open pit $(O P)$ to underground (UG) transition in coal mining. Studia Geotechnica et Mechanica, Vol. 38, No. 3, p.p. 35-48 (2016)

3. R. Brummer, H. Li, A. Moss, The Transition from Open Pit to Underground Mining: an Unusual Slope Failure Mechanism at Palabora. Proceedings Int. Symposium on Stability of Rock Slopes, Cape Town (2006)

4. A.D. Campbell, E. Mu, C.R. Lilley, Cave propagation and open pit interaction at the Ernest Henry mine. Seventh international conference and exhibition on mass mining, Sydney. Hoek E., Bray J., 1981: Rock Slope Engineering, 3rd eds. IMM. London (2016)

5. D. Díaz, Geomechanical status and action plans for interaction between Andina subsidence crater and Los Bronces pit, MSc thesis, Universidad de Los Andes, Santiago (2014)

6. Institute of Mining Science and Technology, Unpublished materials, Hanoi, Vietnam (2012)

7. Itasca, User's Manual of FLAC v. 7.0. Minneapolis, MN, Itasca Consulting Group Ltd. Available at www.itascacg.com (2011)

8. S. Knothe, Asymmetric function of distribution of mining exploatation influences in the medium with changing properties. Archives of Mining Sciences, Vol. 50, Issue 4, pp. 401-415 (2005)

9. N. Mohammad, D.J. Reddish, L.R. Stace, Technical note: the relation between in Situ and laboratory rock properties used in numerical modelling. Int. J. Rock Mech. Min. Sci. Vol. 34, No. 2, pp. 289-297 (1997)

10. M. Bai, F. Kendorski, D. Van Roosendaal, Chinese and North American high-extraction underground coal mining strata behavior and water protection experience and guidelines. Proceedings of the 14th International Conference on Ground Control in Mining, Morgantown (1995)

11. W. Nawrot, Właściwości mechaniczne utworów skalnych o strukturze blokowo-warstwowej, Praca Doktorska, Kraków (1972)

12. H. Yavuz, An estimation method for cover pressure re-establishment distance and pressure distribution in the goaf of longwall coal mines. International Journal of Rock Mechanics and Mining Science, Vol. 41, pp. 193-205 (2004) 